J. Dairy Sci. 95:7195-7199

http://dx.doi.org/10.3168/jds.2011-5171

(C) American Dairy Science Association ${ }^{\circledR}, 2012$.

\title{
Short communication: Automatic washing of hooves can help control digital dermatitis in dairy cows
}

\author{
Peter T. Thomsen, ${ }^{\star 1}$ Annette Kjær Ersbøll, $\dagger$ and Jan Tind Sørensen* \\ ${ }^{*}$ Aarhus University, Department of Animal Science, PO Box 50, DK-8830 Tjele, Denmark \\ †University of Southern Denmark, Faculty of Health Sciences, National Institute of Public Health, Øster Farimagsgade 5A, \\ DK-1353 København K, Denmark
}

\section{ABSTRACT}

The objectives of this study were to develop and test a system for automatic washing of the hooves of dairy cows and to evaluate the effect of frequent automatic washing on the prevalence of digital dermatitis (DD). An automatic hoof washer was developed in an experimental dairy herd and tested in 6 commercial dairy herds in 2 experiments ( 1 and 2 ). In the experimental herd, automatic hoof washing resulted in cleaner hooves. In experiments 1 and 2, cows were washed after each milking on the left side only, leaving the right side unwashed as a within-cow control. In experiment 1, hooves were washed with a water and $0.4 \%$ soap solution. In experiment 2, hooves were washed with water only. In each experiment, DD was scored in a hooftrimming chute approximately $60 \mathrm{~d}$ after the start of hoof washing. Data were analyzed using a generalized linear mixed model. The outcome was the DD status of each leg (DD positive or DD negative). Herd and cow within herd were included as random effects, and treatment (washing or control) was included as a fixed effect. The statistical analyses showed that the odds ratio of having DD was 1.48 in the control leg compared with the washed leg in experiment 1 . In experiment 2 , the odds ratio of having DD was 1.27 in the control leg compared with the washed leg. We concluded that automatic washing of hooves with water and soap can help decrease the prevalence of DD in commercial dairy herds.

Key words: digital dermatitis, dairy cow, hoof washer, automatic hoof washing

\section{Short Communication}

Digital dermatitis (DD) is a major problem for dairy cows in many western countries. Digital dermatitis

\footnotetext{
Received November 22, 2011.

Accepted August 28, 2012.

${ }^{1}$ Corresponding author: petert.thomsen@agrsci.dk
}

causes pain and lameness in infected cows, negatively affecting animal welfare (Rodriguez-Lainz et al., 1999; Laven and Proven, 2000). Digital dermatitis has also been shown to reduce milk production in affected cows (Cooke and Bennett, 2005; Losinger, 2006).

The precise pathogenesis of DD lesions is still unknown. The lesions appear to be associated with several bacterial species, with spirochaetes being the predominant type (Read et al., 1992; Döpfer et al., 1997; Yano et al., 2010). Logue (2011) argued that dirty underfoot conditions are a risk factor for $\mathrm{DD}$, in part because of the presence of bacteria causing DD in the slurry found in modern loose-housing systems. However, very few studies have focused on the relationship between the hygiene or cleanliness of the hooves and lower legs and the prevalence of DD. Rodriguez-Lainz et al. (1996) found that the odds of having a higher proportion $(>5 \%)$ of cows with DD was approximately 20 times higher on dairy farms with muddier corrals than on dairy farms with drier corrals; they suggested this was due to the hooves being in a wet and unhygienic environment. Wells et al. (1999) found that flooring type was associated with the incidence of DD and suggested that a higher incidence of DD was caused by the exposure of hooves to continual moisture and slurry. Hultgren and Bergsten (2001) studied the effects of rubber flooring in tie stalls on cow cleanliness and hoof health and found that cows on rubber-slatted floors were significantly cleaner and had a lower prevalence of DD. Additional studies are needed to further characterize the relationship between hygiene and DD.

Systematic washing of hooves have been suggested as a means to control DD. Anecdotal evidence from some Danish dairy farmers indicates that manual washing of hooves can decrease the prevalence of DD in the herd. However, manual washing is time consuming and the quality of the cleaning may vary. Systematic and frequent automatic washing of hooves may result in better hoof hygiene, decrease water consumption, and decrease labor requirements. The objectives of this study were to develop and test a system for automatic washing of the hooves of dairy cows and to evaluate the 
effect of frequent automatic washing on the prevalence of DD.

An automatic system for hoof washing (Figure 1) was developed by Aarhus University in cooperation with a commercial company (Aqua-Cleaner, Hee, Denmark). A prototype of the hoof washer was tested in an experimental dairy herd (Danish Cattle Research Centre, Foulum, Denmark) to evaluate the ability of the hoof washer to consistently clean hooves and to evaluate the consumption of water and electricity and the duration of washing. The hoof washer was installed immediately after the exit from the milking robot and washed the legs of the cows as they passed through the hoof washer. The washing was done using 4 high-pressure nozzles spraying water at the hoof and lower part of the leg. A sensor recorded the presence of a cow in the hoof washer and controlled the timing of spraying in relation to the position of the cow. Washing was done using a soap solution (tap water mixed with $0.4 \%$ soap, Hoof Cleaner HC 40; DeLaval, Drongen, Belgium).

Cows at the Danish Cattle Research Centre were housed in 3 groups in a loose-housing system with 3 milking robots, cubicles with rubber mattresses, and slatted concrete floors. Floors were scraped by a robot scraper (Lely Discovery; Lely, Maassluis, the Netherlands). Housing, feeding, management, distribution of lactation stage, and parity (and thus the production level) did not differ between the 3 groups of cows. The only difference was that 1 group of 38 cows had a hoof washer installed after the exit from the milking robot. No hoof washing was done in the other 2 groups of cows (76 cows). The hygiene of all hooves (distal to the dew claws) was recorded in all 3 groups of cows using the scoring system described by Schreiner and Ruegg (2002). Cows were given a score from 1 to 4, in which 1 was given to hooves being completely or almost completely clean, 2 to hooves being slightly dirty, 3 to hooves mostly covered with dirt or manure, and 4 to hooves completely covered with dirt or manure. The evaluation of cleanliness was done by the same observer 3 times with approximately $1 \mathrm{wk}$ in between. The evaluation was done at a fixed time in the morning; thus, some cows in the group with the hoof washer were scored a few minutes after having their hooves washed, whereas other cows were scored up to $12 \mathrm{~h}$ after having their hooves washed (not being milked for up to $12 \mathrm{~h}$ before the scoring).

After the evaluation at the Danish Cattle Research Centre, a few technical adjustments to the hoof washer were done and an improved version of the hoof washer was tested in 6 commercial dairy herds in Jutland, Denmark. Herds were selected by convenience sampling based on information from local veterinarians and cattle advisors. To evaluate the functionality of the hoof washer in combination with different milking systems, 4 of the herds had milking parlors (2 parallel or herringbone, 2 carousels) and 2 had automatic milking systems (AMS). All herds had loose-housing systems with cubicles (rubber mattresses and a small amount of straw or sawdust bedding) and solid or slatted concrete floors (2 solid and 4 slatted floors). Cows on the 6 dairies did not have access to outdoor lots or pasture. All herds had a moderate to high prevalence of DD (20 to $40 \%$ ) at the start of the study.

All lactating cows in the herds were washed after each milking (twice daily in all herds except AMS herds, in which the number of washings equaled the number of visits to the milking robot). During the first half of the trial (experiment 1, April to October 2009), cows were washed on the left side only with tap water and a $0.4 \%$ soap solution, leaving the right side unwashed as a within-cow control. No other means (e.g., hoof baths or other means of disinfection) were used to control DD. After experiment 1, the hoof washer was removed for 4 mo. These 4 mo served as a wash-out period before the second part of the trial (experiment 2), which took place in February to July 2010. The hoof washer was reinstalled in the herds in January 2010. Experiment 2 was identical to experiment 1 with one exception: this time, only tap water was used to wash the hooves (i.e., no soap was added to the water).

Farmers were allowed to treat individual cows with severe cases of DD, typically using bandages containing salicylic acid (Vet-Flex; Kruuse, Langeskov, Denmark). All such treatments were recorded, and cows with one or both hind legs treated with a bandage containing salicylic acid were excluded from the analyses.

Before the start of each experiment, approximately 90 cows were selected randomly from each herd $(60$ to 70 in AMS herds, corresponding to the number of cows milked by 1 milking robot). Before the initiation of experiments 1 and 2 and at, on average, $59 \mathrm{~d}$ (experiment 1 , range of 49 to $85 \mathrm{~d}$ ) and $64 \mathrm{~d}$ (experiment 2, range of 47 to $90 \mathrm{~d}$ ) after the initiation of hoof washing, cows were examined to determine the presence of DD. Cows were examined in a hoof-trimming chute and trimmed by a professional trimmer if needed. Hooves were washed to facilitate the observation of DD lesions. All hooves were examined for DD lesions, and any observed DD lesions were recorded using the scoring system described by Manske et al. (2002). In short, DD lesions were scored on a 6 -point scale, in which score 0 indicated no lesions, scores 1, 2, and 3 indicated early stages of DD, score 4 indicated late stages of DD, and score 5 indicated healing or healed lesions. Legs with DD scores of $1,2,3,4$, and 5 were defined as DD positive, and legs with a DD score of 0 were defined as DD negative. 


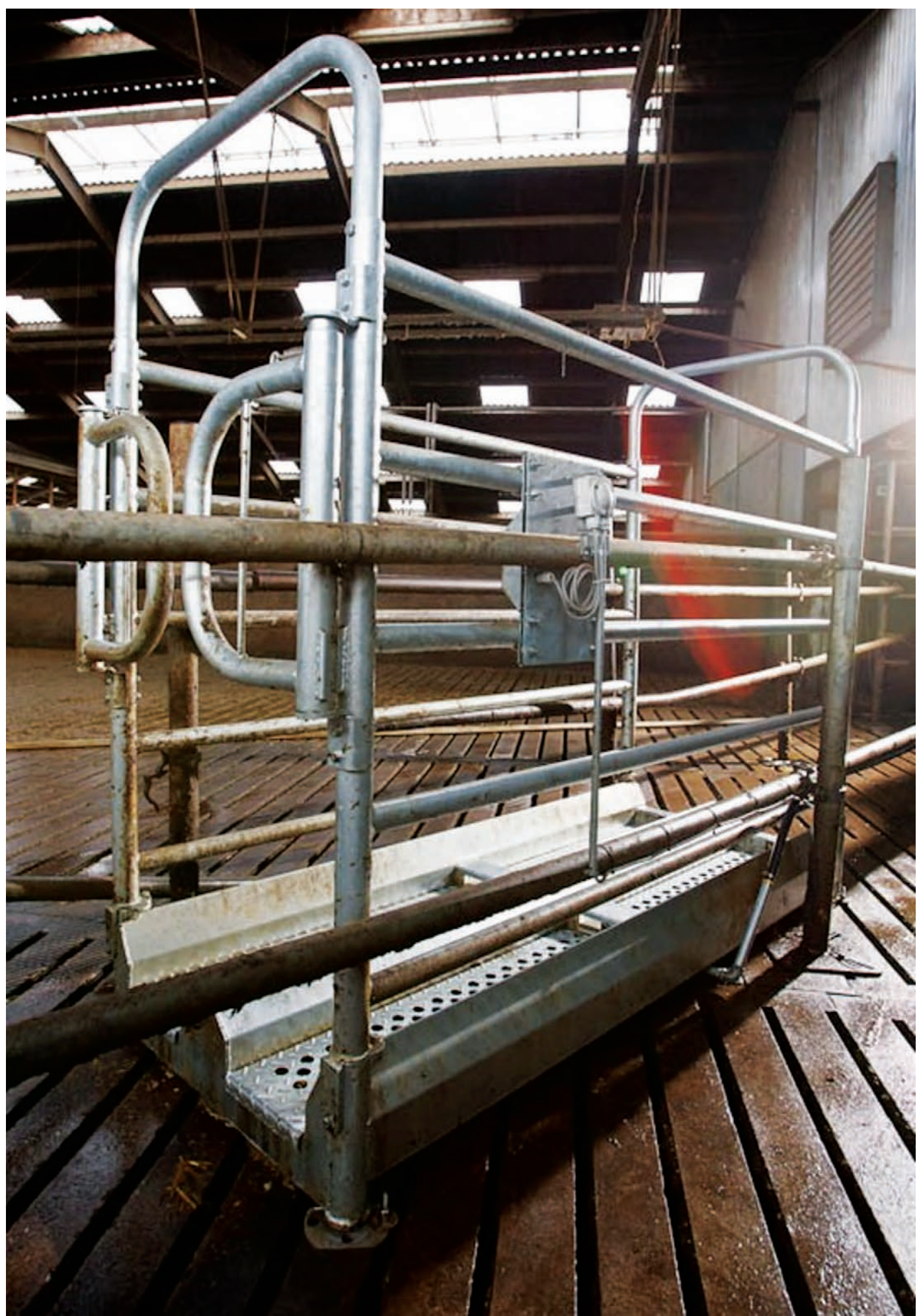

Figure 1. Automatic hoof washer used in this study to evaluate the effect of automatic washing of hooves on the prevalence of digital dermatitis in 6 commercial dairy herds. Color version available in the online PDF. 
Only hind legs were included in the analyses because of the very low number of cases of DD on the front legs. Statistical analysis regarding experiment 1 included only 5 of the 6 herds because in 1 herd, the water pressure was too low in the barn to ensure proper functioning of the hoof washer. This problem was corrected in experiment 2.

Data were analyzed using a generalized linear mixed model with a binomial distribution and a logit link function (PROC GLIMMIX, SAS version 9.2; SAS Institute Inc., Cary, NC). The outcome was the DD status of each leg (DD positive or DD negative). Herd and cow within herd were included as random effects, and treatment (washing or control) was included as a fixed effect. This resulted in a within-cow comparison of treatments (i.e., comparison of washed and control $\operatorname{legs})$.

The evaluation at the Danish Cattle Research Centre showed that the consumption of water was $2 \mathrm{~L} /$ wash per cow (all 4 hooves washed). The hoof washer used $0.4 \mathrm{~kW} \cdot \mathrm{h}$ of electricity per cow per month. Washing of the hooves of each cow took approximately $3 \mathrm{~s}$. Figure 2 presents the distribution of hygiene scores in washed and unwashed cows.

Before the start of hoof washing, the prevalence of DD was not significantly different on the left (treatment) and right (control) hind legs (experiment 1: 28.6 vs. $29.6 \%, P=0.44$; experiment 2 : 29.2 vs. $30.4 \%, P$ $=0.72$ ). A total of 11 and 8 cows (washed and control legs, respectively) in experiments 1 and 5 , and 3 cows in experiment 2 were excluded from the analyses because

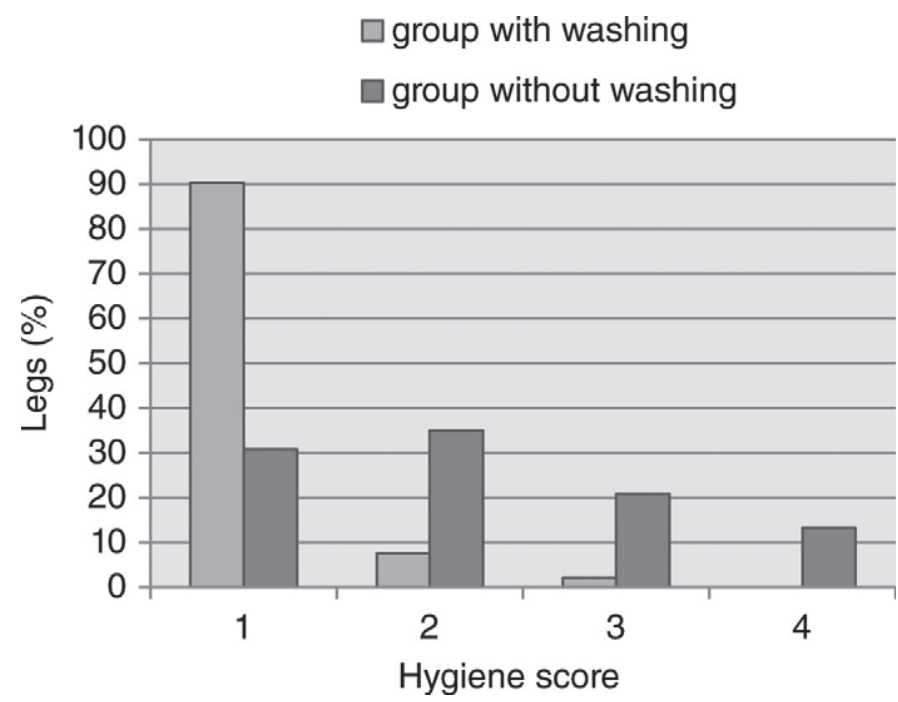

Figure 2. Distribution of hygiene scores in cows with $(\mathrm{n}=38)$ and without $(\mathrm{n}=76)$ automatic washing of hooves. Hygiene score: 1 $=$ hooves completely or almost completely clean; $2=$ hooves slightly dirty; $3=$ hooves mostly covered with dirt or manure; $4=$ hooves completely covered with dirt or manure. of individual treatments. In experiment 1 , at the end of the intervention, 197 cows $(52.3 \%)$ had no DD, 69 cows (18.3\%) had DD in both hind legs, 70 cows $(18.6 \%)$ had DD in the control leg only, and 41 cows $(10.9 \%)$ had DD in the washed leg only. In experiment 2, 273 cows $(56.3 \%)$ had no DD, 81 cows $(16.7 \%)$ had DD in both hind legs, 75 cows $(15.5 \%)$ had DD in the control leg only, and 56 cows (11.5\%) had DD in the washed leg only. The statistical analyses showed that the odds ratio of having DD was $1.48(P=0.02)$ in the control leg compared with the washed leg in experiment 1 . In experiment 2 , the odds ratio of DD was $1.27(P=0.13)$ in the control leg compared with the washed leg.

Our results indicate that automatic washing has the potential to help decrease the prevalence of DD in commercial dairy herds because the prevalence of DD was lower in the legs being washed compared with the control legs when the legs were washed with water and soap. When the legs were washed with water only, the positive effect of washing was not statistically significant.

Digital dermatitis is a serious problem in dairy production in many countries, and it appears to be increasing in prevalence (Logue, 2011). Traditionally, hoof baths with disinfectants have been used to control contagious hoof disorders (Laven and Logue, 2006). However, some studies have shown that hoof baths have no or only a limited effect on the prevalence of DD (Laven and Logue, 2006; Thomsen et al., 2008), and many of the chemicals traditionally used in hoof baths have undesired side effects on health (e.g., formalin) or the environment (e.g., copper sulfate). At the same time, labor is limited on modern dairy farms. Dairies are working to minimize labor hours per cow; thus, equipment and management practices that can help dairy producers diagnose, prevent, and treat diseases in cattle with a minimal amount of manual labor are desirable (Leach et al., 2010). Therefore, a method that has the potential to help prevent DD without the use of adverse chemicals or an extensive amount of labor may be of interest to many dairy farmers.

Parity, stage of lactation, season, and different herd characteristics have been shown to influence the prevalence of DD (Rodriguez-Lainz et al., 1999; Holzhauer et al., 2006; Barker et al., 2009). Therefore, a study design using the cow as its own control, as in the present study, is a very robust way of evaluating the effect of automatic washing of hooves or other measures intended to decrease the prevalence of DD.

Washing hooves on only one side of cows allows bacteria that cause DD to remain essentially undisturbed on the control hooves. Thus, infectious pressure on the washed hooves in experiments 1 and 2 may have been higher than what would be encountered in a commer- 
cial setting, where all legs of the cows would be washed. Therefore, the positive effect of washing found in this study most likely is an underestimation of the true effect of hoof washing.

In conclusion, automatic washing of hooves with a soap solution can help decrease the prevalence of DD in modern dairy production. The automatic washing of hooves was shown to be effective without the use of antibiotics or other chemicals and required only minimal labor, and therefore may be a practical way of controlling DD in modern dairy production.

\section{ACKNOWLEDGMENTS}

The project was financially supported by The Innovation Law, Danish Ministry of Food, Agriculture and Fisheries (Copenhagen). The study sponsor had no influence on the collection, analysis, or interpretation of data. The hoof washer is currently commercially available. Aarhus University owns part of a patent and therefore has a commercial interest in the hoof washer.

\section{REFERENCES}

Barker, Z. E., J. R. Amory, J. L. Wright, S. A. Mason, R. W. Blowey, and L. E. Green. 2009. Risk factors for increased rates of sole ulcers, white line disease, and digital dermatitis in dairy cattle from twenty-seven farms in England and Wales. J. Dairy Sci. 92:1971-1978.

Cooke, R. J., and R. M. Bennett. 2005. The costs and benefits of digital dermatitis control on UK dairy farms. Cattle Pract. 13:239-242.

Döpfer, D., A. A. H. M. ter Huurne, J. L. Cornelisse, A. J. A. M. van Asten, A. Koopmans, F. A. Meijer, Y. H. Schukken, I. Szakall W. Klee, and R. B. Bosma. 1997. Histological and bacteriological evaluation of digital dermatitis in cattle, with special reference to spirochaetes and Campylobacter faecalis. Vet. Rec. 140:620-623.
Holzhauer, M., C. Hardenberg, C. J. M. Bartels, and K. Frankena. 2006. Herd- and cow-level prevalence of digital dermatitis in the Netherlands and associated risk factors. J. Dairy Sci. 89:580-588.

Hultgren, J., and C. Bergsten. 2001. Effects of a rubber-slatted flooring system on cleanliness and foot health in tied dairy cows. Prev. Vet. Med. 52:75-89.

Laven, R. A., and D. N. Logue. 2006. Treatment strategies for digital dermatitis for the UK. Vet. J. 171:79-88.

Laven, R. A., and M. Proven. 2000. Use of an antibiotic footbath in the treatment of bovine digital dermatitis. Vet. Rec. 147:503-506.

Leach, K. A., H. R. Whay, C. M. Maggs, Z. E. Barker, E. S. Paul, A. K. Bell, and D. C. J. Main. 2010. Working towards a reduction in cattle lameness: 1 . Understanding barriers to lameness control on dairy farms. Res. Vet. Sci. 89:311-317.

Logue, D. 2011. Understanding bovine digital dermatitis. Vet. Rec. $168: 212-213$

Losinger, W. C. 2006. Economic impacts of reduced milk production associated with papillomatous digital dermatitis in dairy cows in the USA. J. Dairy Res. 73:244-256.

Manske, T., J. Hultgren, and C. Bergsten. 2002. Topical treatment of digital dermatitis associated with severe heel-horn erosion in a Swedish dairy herd. Prev. Vet. Med. 53:215-231.

Read, D. H., R. L. Walker, A. E. Castro, J. P. Sundberg, and M. C. Thurmond. 1992. An invasive spirochaete associated with interdigital papillomatosis of dairy cattle. Vet. Rec. 130:59-60.

Rodriguez-Lainz, A., D. W. Hird, T. E. Carpenter, and D. H. Read. 1996. Case-control study of papillomatous digital dermatitis in southern California dairy herds. Prev. Vet. Med. 28:117-131.

Rodriguez-Lainz, A., P. Melendez-Retamal, D. W. Hird, D. H. Read, and R. L. Walker. 1999. Farm- and host-level risk factors for papillomatous digital dermatitis in Chilean dairy cattle. Prev. Vet. Med. 42:87-97.

Schreiner, D. A., and P. L. Ruegg. 2002. Effects of tail docking on milk quality and cow cleanliness. J. Dairy Sci. 85:2503-2511.

Thomsen, P. T., A. K. Ersb $\varnothing l l$, and J. T. Sørensen. 2008. Evaluation of three commercial hoof-care products used in footbaths in Danish dairy herds. J. Dairy Sci. 91:1361-1365.

Wells, S. J., L. P. Garber, and B. A. Wagner. 1999. Papillomatous digital dermatitis and associated risk factors in US dairy herds. Prev. Vet. Med. 38:11-24.

Yano, T., K. K. Moe, K. Yamazaki, T. Ooka, T. Hayashi, and N. Misawa. 2010. Identification of candidate pathogens of papillomatous digital dermatitis in dairy cattle from quantitative $16 \mathrm{~S}$ rRNA clonal analysis. Vet. Microbiol. 143:352-362. 